\title{
Evaluation of categories of intrapartum fetal heart rate tracings in pregnancies complicated with fetal growth restriction and its relation to perinatal outcome
}

\author{
Bhavya H. U.* \\ Department of Obstetrics and Gynecology, KVG Medical College and Hospital, Sullia, Dakshina Kannada District,
} Karnataka, India

Received: 18 January 2021

Accepted: 11 February 2021

\section{*Correspondence:}

Dr. Bhavya H. U.,

E-mail: bhavyahu.obg@gmail.com

Copyright: $(\odot)$ the author(s), publisher and licensee Medip Academy. This is an open-access article distributed under the terms of the Creative Commons Attribution Non-Commercial License, which permits unrestricted non-commercial use, distribution, and reproduction in any medium, provided the original work is properly cited.

\begin{abstract}
Background: Intrapartum FHR monitoring is widely used during labour as changes in FHR precede brain injury, so timely response to abnormal FHR patterns might be effective in preventing it. There is a strong association between stillbirth and FGR which warrants intensive intrapartum fetal surveillance for optimal perinatal outcome. In this study we aimed to classify intrapartum FHR tracings into different categories in FGR pregnancies and correlate with perinatal outcome.

Methods: A total 100 singleton pregnant women $>34$ weeks gestation with FGR were included in study. FHR tracings were followed throughout first and second stage of labour. FHR tracing were categorized into NICHD 3-tier classification as category I, II and III. Maternal and neonatal outome in each category were analysed.

Results: Mean duration of category I tracings was 9.05 hours, category II was 7.66 hours and that of category III was 0.49 hours. During late active phase 25/95 patients with category I FHR tracings had vaginal delivery, 62/95 had category II FHR tracings, of which $95.1 \%$ had vaginal delivery and $4.9 \%$ had instrumental. $8 / 95$ with category III FHR tracings required caesarean section. All patients with category I tracings had normal neonatal outcome, among patients with category II FHR tracings, $74.6 \%$ had normal whereas $25.4 \%$ had adverse outcome, all with category III FHR tracings had adverse outcome.

Conclusions: Categorizing FHR tracings is helpful to distinguish neonates who are likely to have normal outcome from those who are at risk for fetal hypoxia. When the category II tracings are present, it requires more vigilant monitoring and decision taking.
\end{abstract}

Keywords: Categorization, Fetal growth restriction, Fetal heart rate, National Institute of Child Health and Human Development, Perinatal outcome

\section{INTRODUCTION}

Intrapartum electronic fetal heart rate monitoring is being used widely throughout the world for monitoring labour especially in high risk pregnancy. ${ }^{1-3}$ Rationale for fetal heart monitoring is that the changes in fetal heart rate precede brain injury. ${ }^{4}$ Therefore timely responses to abnormal fetal heart patterns might be effective in preventing brain injury. Thus, it could be useful in reducing adverse outcomes and professional liability claims. It has been seen that it only reduces the incidence of neonatal seizures but has no beneficial effect in decreasing cerebral palsy or neonatal mortality. On the other hand, its use is found to be associated with increased operative interventions during labour. ${ }^{5}$

The most plausible explanation for failure of electronic fetal monitoring (EFM) is inadequate skills in the interpretation of cardiotocographs (CTGs), lack of standardization of CTG terminology and failure to take 
appropriate action once abnormalities have been detected. There is considerable inter and intra observer variability in the interpretation of FHR tracings. Therefore to maximize the potential benefits of intrapartum FHR monitoring, it is essential that standardization of EFM interpretation and management of abnormalities should be evidence based and practical.

Various classification systems have been proposed worldwide for the standardized interpretation of intrapartum FHR patterns with or without management and clinical guidelines have been formulated. In 2001 in UK, Royal College of Obstetricians and Gynaecologists (RCOG) classified FHR patterns as normal, suspicious and pathological. ${ }^{6}$ In 2007, Society of Obstetricians and Gynecologists of Canada (SOGC) classified FHR patterns as normal, atypical and abnormal. ${ }^{4}$ In 2008 in USA, American College of Obstetricians and Gynecologists (ACOG) classified FHR patterns as category I, II and III. ${ }^{7}$ On the other hand, Japan Society of Obstetrics and Gynaecology (JSOG) in 2010 proposed intrapartum management guidelines based on 5-tier classification system. ${ }^{8}$ Continuous electronic fetal monitoring is considered appropriate for women in labour with high risk of fetal hypoxia as in pregnancies complicated by fetal growth restriction (FGR). Outcome of FGR pregnancies could be improved by standardized interpretation and management of EFM.

Fetal growth restriction (FGR) represents pathological inhibition of fetal growth and failure of the fetus to attain its growth potential. ${ }^{9}$ There is a strong association between stillbirth and fetal growth restriction. ${ }^{10}$ Several years after birth, $30 \%$ of IUGR babies remain below $30^{\text {th }}$ percentile for weight of children of their age and only 10 to $20 \%$ above the $50^{\text {th }}$ percentile. ${ }^{11}$ Therefore, FGR in pregnancy warrants intensive antepartum and intrapartum fetal surveillance to ensure optimal perinatal outcome. Majority of the growth compromised fetus will reflect their hypoxemic status during labour by some abnormality in FHR pattern.

In the present study we aim to classify the intrapartum fetal heart rate tracings into different categories according to National Institute of Child Health and Human Development (NICHD) 3-tier system in pregnancy with FGR and correlate this with the perinatal outcome. ${ }^{12}$

\section{METHODS}

The present study was a hospital based prospective observational study done on 100 pregnant women with FGR of >34 weeks of gestation in labour (spontaneous or induced) admitted in labour ward at a tertiary care centre in Karnataka, South India, from June 2017 till December 2018 after obtaining institutional ethical committee clearance. All those cases with contraindications to vaginal delivery like central placenta praevia, contracted pelvis, previous 2 LSCS were excluded from the study. After taking informed consent, fetal monitoring by cardiotocography was done in all patients. Simultaneous recordings of FHR and uterine pressure were performed by CTG machine (BPL machine, Model no. 9534). An ultrasound coupling gel was applied to the transducer and placed over the maternal abdomen. The pressuresensitive contraction transducer, called a tocodynamometer was fixed to the skin by a band around the belly.

Initial FHR tracing of 20 minutes was obtained in all the pregnant women who were enrolled in the study at the onset of labour and it was reviewed for all the FHR parameters. The details of progress of labour were recorded. Details of induction and augmentation with prostaglandins, oxytocin and timing of ARM were all noted. FHR tracings were followed throughout the first and second stage of labour. During the first stage of labour FHR tracing was obtained once in every 15 minutes and in second stage of labour it was done for every 5minutes. Each fetal heart rate tracing evaluated for baseline, variability, and presence or absence of accelerations and decelerations and then categorized each tracing into the current NICHD 3-tier classification system as category I, II and III. Duration of all the 3 categories during the first and second stage of labour was recorded. Any transition between the categories was also noted. When the tracings changed from category I to category II and III all measures taken to revert it back and duration of change was also noted. Management of the FHR tracings was done as per the hospital protocol.

Maternal outcome included mode of delivery and neonatal outcomes included birth weight, Apgar scores, umbilical artery $\mathrm{pH}$, admission to the neonatal intensive care unit (NICU). The final result at the end was analyzed and the outcome was interpreted in terms of: 1) Correlation of the mean duration of FHR tracing in all three categories in late active phase of labour with perinatal outcome. 2) Total number of neonates with normal and adverse perinatal outcome. (Adverse neonatal outcome was measured in terms of apgar score $<7$ at 1 and 5 minutes, umbilical cord $\mathrm{pH}<7.2$ and admission to NICU due to complications of intrapartum hypoxia). 3) Correlation of the last FHR tracing within half an hour of delivery with cord blood $\mathrm{pH}$ immediately after the birth, apgar scoring at 1 and 5 minutes, admission to NICU and the duration of hospital stay.

\section{Statistical analysis}

The data was computerized. Statistical analysis of the observations and the results of the above study were carried out using the two standard test of significance in order to find if the results were statistically significant. Continuous data such as age, height, weight etc. were described by mean and standard deviation and these were compared by student t-test. Categorical data like FHR patterns were described by frequency, duration and percentage and were compared by chi-square test. 


\section{RESULTS}

\section{Demographic characteristics}

Mean age of women in study was $24.5 \pm 3.4$ years. Primipara: 58\%; multipara: $31 \%$ and grand multipara $11 \%$.

Risk factors were present in $41 \%$ which included gestational hypertention, anaemia, hypothyroidism, bad obstetric history and others.

\section{Gestational age at delivery}

A total $60 \%$ of women delivered at gestational age of 37 weeks and above whereas $40 \%$ delivered at the gestational age less than 37 weeks.

\section{Labour characteristics}

In the present study, out of 100,39 patients were in spontaneous labour. However, labour was induced in 61 subjects.

\section{Duration of labour}

In the present study, it was observed that, the mean duration of latent phase of labour was 6.24 \pm 3.1 hours, active phase was $4.7 \pm 1.5$ hours and that of second stage of labour was $0.5 \pm 0.15$ hours. Overall mean duration of labour was $11 \pm 4.7$ hours.

Category of FHR tracing during labour and its relation to perinatal outcome

In the present study, FHR tracing was obtained in all stages of labour. These tracings were analysed and categorized into category I, II and III. The mean duration of category I was 9.05 hours, mean duration of category II was 7.66 hours and that of category III was 0.49 hours (Figure 1).

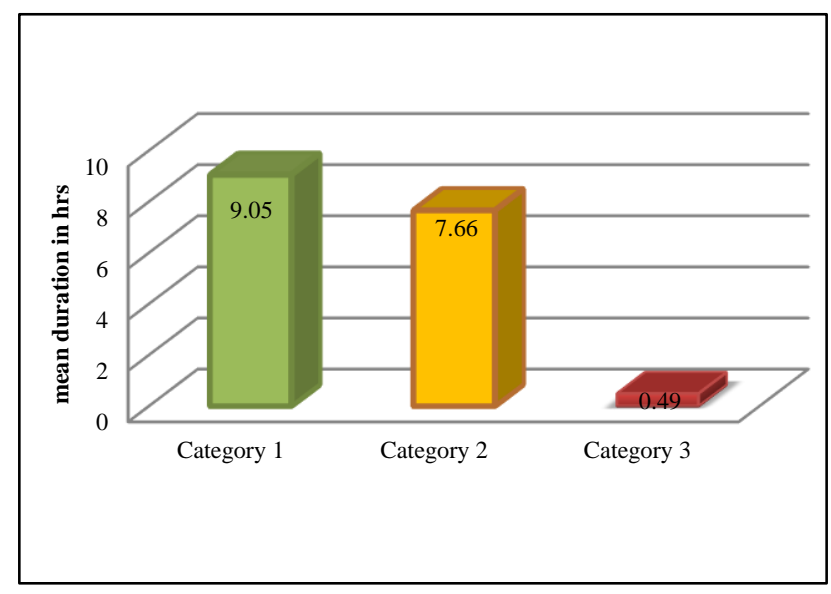

Figure 1: Mean duration of category of FHR tracing during labour.
Correlation of overall category of FHR tracing in late active phase with mode of delivery and neonatal outcome

All 10 patients with category I FHR tracings (10/95) from the beginning of labour till delivery, had normal vaginal delivery and normal neonatal outcome.

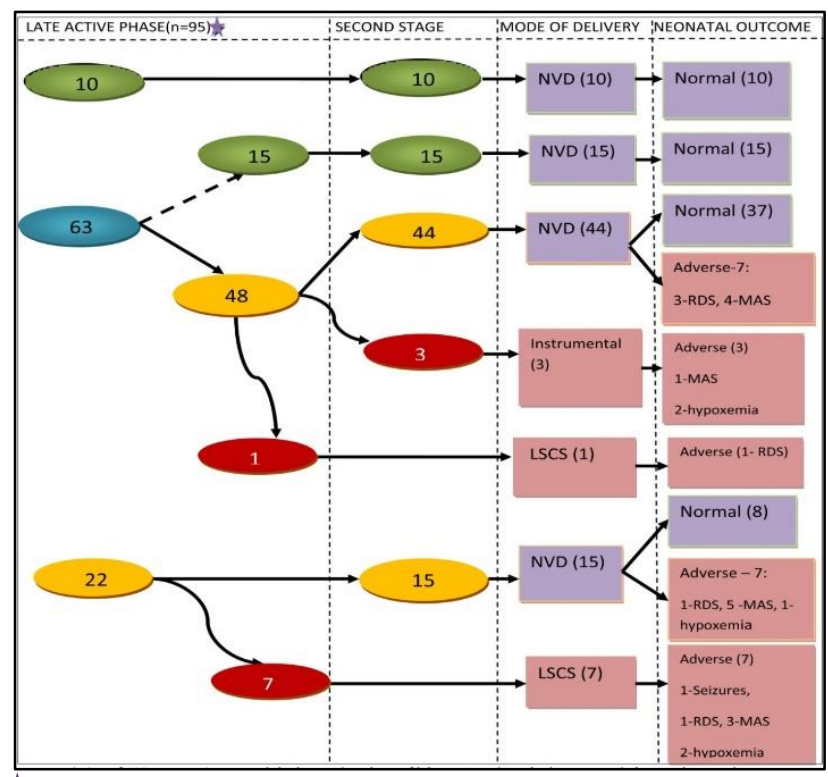

Jut of 100 women, 95 entered the late active phase of labour. 4 patients had caesarean in latent phase and one had caesarean in early active phase of labour.

Figure 2: Category of FHR tracing in late active phase and second stage of labour and its relation with mode of delivery and neonatal outcome.

A total of 63/95 patients $(66.3 \%)$ whose FHR tracing was in category I during latent phase, progressed to category II in late active phase of labour. 15 patients reverted back to category I and had normal vaginal delivery with normal neonatal outcome $(\mathrm{p}=0.0001)$. However, in 48 $(50.5 \%)$ patients the FHR tracings did not revert back to category I. One patient FHR tracings progressed to category III in the late active phase and required LSCS had adverse neonatal outcome. In 3 patients, FHR tracings progressed to category III during second stage, required instrumental delivery and had adverse neonatal outcome. Remaining 44/48 women had their FHR tracings in category II till delivery and had normal vaginal delivery. When neonatal outcome was assessed, $37 / 44(84 \%)$ had normal whereas the remaining $7(16 \%)$ had adverse neonatal outcome $(\mathrm{p}=0.0001)$ (Figure 2$)$.

22/95 patients had FHR tracings in category II in latent phase of labour. $7 / 22$ progressed to category III in active phase and required LSCS had adverse neonatal outcome. The remaining 15/22 continued in category II FHR tracings till delivery and had normal vaginal delivery but when the neonatal outcome was assessed, 8/15 had normal and remaining 7 had adverse neonatal outcome. 


\section{Maternal outcome}

In the present study it was observed that, majority of the patients i.e. $84 \%(84 / 100)$ had normal vaginal delivery, $13 \%(13 / 100)$ had caesarean section and 3\% (3/100) of them had instrumental vaginal delivery (Figure 3).

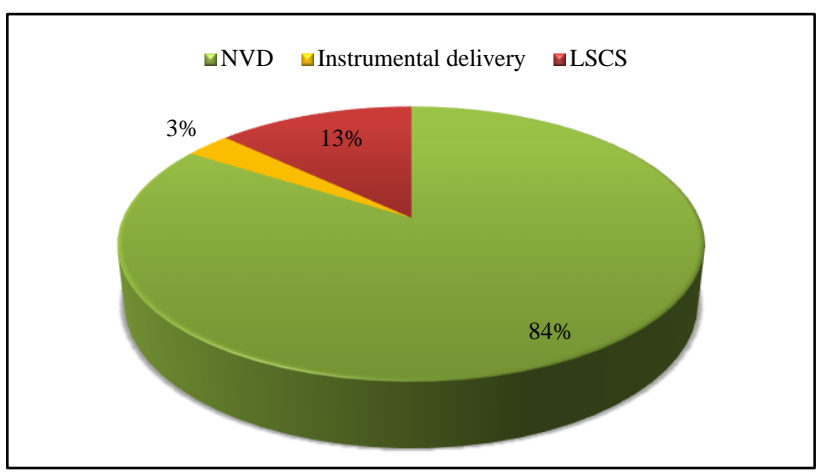

Figure 3: Mode of delivery.

\section{Correlation of overall category of FHR tracing in late} active phase with mode of delivery

A total of $25 / 95$ patients who had category I FHR tracings during late active phase, had normal vaginal delivery $(100 \%, \mathrm{p}=0.0001)$. 62/95 patients had category II FHR tracings during late active phase, of which 59 patients $(95.1 \%)$ had normal vaginal delivery and the rest 3 patients $(4.9 \%)$ had instrumental vaginal delivery $(\mathrm{p}=0.0001) .8$ out of 95 patients had category III FHR tracings during late active phase and required caesarean section $(100 \%, \mathrm{p}=0.0001)$. The indication for caesarean was fetal bradycardia with recurrent decelerations and MSL in all patients (Table 1).

Table 1: Category of FHR tracings in late active phase and its relation to mode of delivery.

\begin{tabular}{|lllll|}
\hline $\begin{array}{l}\text { Category } \\
\text { of FHIR } \\
\text { tracings } \\
\text { (n=95) }\end{array}$ & $\begin{array}{l}\text { NVD } \\
(\mathbf{8 4})\end{array}$ & $\begin{array}{l}\text { Instrumental } \\
\text { delivery (3) }\end{array}$ & $\begin{array}{l}\text { Caesarean } \\
\text { section } \mathbf{( 8 )}\end{array}$ & P value \\
\hline $\begin{array}{l}\text { Category } \\
\text { I (25) }\end{array}$ & 25 & 0 & 0 & 0.0001 \\
\hline $\begin{array}{l}\text { Category } \\
\text { II (62) }\end{array}$ & 59 & 3 & 0 & 0.0001 \\
\hline $\begin{array}{l}\text { Category } \\
\text { III (8) }\end{array}$ & 0 & 0 & 8 & 0.0001 \\
\hline
\end{tabular}

\section{Neonatal outcome}

In the present study, out of 100 patients, 71 neonates had normal neonatal outcome and 29 neonates had adverse neonatal outcome. Adverse neonatal outcome in the present study was measured in terms of apgar score less than 7 at 1 minute and 5 minutes, umbilical cord $\mathrm{pH}<7.2$ or admission to NICU for complications due to intrapartum hypoxia.
20 neonates had apgar score $<7$ at 1 minute and apgar score $<7$ at 5 minutes was seen in only 1 neonate. Umbilical cord $\mathrm{pH}<7.2$ was observed in $10 \%$ of the neonates. $29 \%(29 / 100)$ of the neonates with adverse outcome were admitted to NICU in which the incidence of respiratory distress was $6 \%$, incidence of hypoxemia was $9 \%$, meconium aspiration was seen in $13 \%$ and neonatal seizures developed in only $1 \%$ (Table 2 ). 11 out of 29 neonates developed complications during NICU stay like sepsis in 5 neonates, jaundice in 4 neonates and 2 neonates developed febrile seizures. Neonatal mortality was not seen in the study population.

Table 2: Normal and adverse outcome in FGR babies $(n=100)$.

\begin{tabular}{|lll|}
\hline Neonatal outcome & No. & $\%$ \\
\hline Normal & 71 & $71 \%$ \\
\hline Adverse & 29 & $29 \%$ \\
\hline Apgar score <7 & & \\
\hline At 1 minute & 20 & $20 \%$ \\
\hline At 5 minutes & 1 & $1 \%$ \\
\hline Umbilical pH <7.2 & 10 & $10 \%$ \\
\hline Admission to NICU(n=29) & & \\
\hline Hypoxemia & 9 & $9 \%$ \\
\hline Respiratorydistress & 6 & $6 \%$ \\
\hline MAS & 13 & $13 \%$ \\
\hline Neonatal seizures & 1 & $1 \%$ \\
\hline
\end{tabular}

Category of FHR tracing half an hour before delivery in women with FGR pregnancy

In the present study, $87 / 100$ patients progressed to second stage of labour. Out of 87,25 patients $(28.7 \%)$ had category I FHR tracings, 59 patients $(63.8 \%)$ had category II FHR tracings and 3 patients (3.5\%) had category III FHR tracings in last half an hour before delivery (Figure 4).

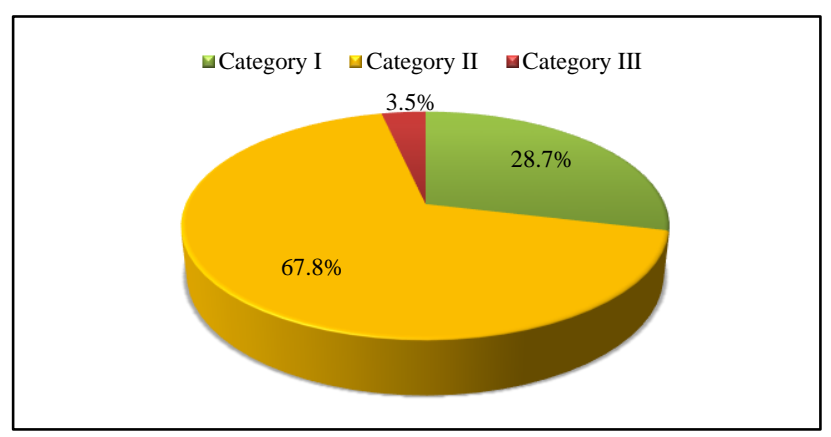

Figure 4: Category of FHR tracing half an hour before delivery.

Category of FHR tracing in last half an hour before delivery and its relation to neonatal outcome

All patients (25/25) with category I tracings had normal neonatal outcome $(100 \%, \mathrm{p}=0.0001), 44$ out of 59 
patients $(74.6 \%)$ who had category II FHR tracings, had normal neonatal outcome whereas 15 patients $(25.4 \%)$ had adverse neonatal outcome $(\mathrm{p}=0.0001)$. All patients (3/3) with category III FHR tracings had adverse neonatal outcome $(100 \%, \mathrm{p}=0.01)$. This progressive increase in adverse neonatal outcome with the advancement of FHR tracing categories was found to be statistically significant (Table 3).

Table 3: Category of FHR tracing in last half an hour before delivery and its relation to neonatal outcome.

\begin{tabular}{|c|c|c|c|c|c|}
\hline \multirow{2}{*}{$\begin{array}{l}\text { Category of FHR } \\
\text { tracing in last half } \\
\text { an hour before } \\
\text { delivery }\end{array}$} & \multicolumn{2}{|c|}{$\begin{array}{l}\text { Normal } \\
\text { outcome } \\
(n=69)\end{array}$} & \multicolumn{2}{|c|}{$\begin{array}{l}\text { Adverse } \\
\text { outcome } \\
(\mathbf{n}=\mathbf{1 8})\end{array}$} & \multirow[t]{2}{*}{ P value } \\
\hline & No. & $\%$ & No. & $\%$ & \\
\hline Category I (25) & 25 & 100 & 0 & 0 & 0.0001 \\
\hline Category II (59) & 44 & 74.6 & 15 & 25.4 & 0.0001 \\
\hline Category III (3) & 0 & 0 & 3 & 100 & 0.014 \\
\hline
\end{tabular}

\section{DISCUSSION}

The objective of intrapartum fetal monitoring is to avoid adverse fetal outcome. It is generally accepted that intermittent auscultation is appropriate for low risk patients but electronic fetal monitoring (EFM) should be used in cases of FGR due to increased risk for fetal hypoxia during labour. ${ }^{12}$ FIGO formulated clinical guidelines in a workshop conducted in 1986 on the clinical use of electronic fetal heart rate monitoring, in order to standardize electronic FHR tracings. ${ }^{13}$ They classified the FHR patterns as normal, suspicious, or pathologic. Later on various three tier classification systems were adopted worldwide under different nomenclatures. In 2001 in UK, Royal College of Obstetricians and Gynaecologists (RCOG) adopted the same nomenclature proposed by FIGO. ${ }^{6}$ In 2007, Society of Obstetricians and Gynaecologists of Canada (SOGC) classified FHR patterns as normal, atypical and abnormal. $^{4}$

In 2008 in US, American College of Obstetricians and Gynaecologists (ACOG) and the NICHD together classified the fetal heart rate patterns as category I, II and III. ${ }^{12}$ In clinical practice it was seen that in three tier system, category II tracings were highly heterogeneous in terms of prediction of risk of acidemia in the neonate. Therefore, Japan Society of Obstetrics and Gynaecology (JSOG) in 2010 proposed intrapartum management guidelines based on 5-tier classification system. ${ }^{8}$ The degree of risk was classified into five levels and was also given colour coding. Level 1 was synonymous to category I and was represented in green. Level 2, 3 and 4 was synonymous to category II and was represented by blue, yellow and orange respectively. Level 5 was synonymous to category III and was represented by colour red. However, 5-tier system was too complex for routine use during labour. Therefore it was realized that three tier classification systems were simpler than 5 tier system in clinical practice. In the present study also three tier system as per NICHD classification was selected for categorizing intrapartum fetal heart rate tracings into category I, II and III.

Blackwell et al conducted a retrospective study to test the intra and inter observer reliability of the NICHD 3-tier classification system. ${ }^{14} 154$ FHR tracings from 40 women with singleton pregnancy were independently reviewed without any clinical data by 3 examiners and the FHR tracings taken during last 3 hours prior to delivery were classified into category I, II and III according to NICHD classification system. They found that majority of the patients i.e. $62.2 \%$ had category II FHR tracings followed by category I FHR tracings seen in $28.3 \%$ and category III tracings were seen in only $1.9 \%$ of patients. Thus Blackwell et al like in the present study also observed category II FHR tracings to be the commonest in last three hours of labour which was equivalent to late active phase of labour of the present study (Table 4).

Table 4: Category of FHR tracings in different stages of labour.

\begin{tabular}{|llll|}
\hline $\begin{array}{l}\text { Phase of } \\
\text { labour }\end{array}$ & Category I & Category II & Category III \\
\hline $\begin{array}{l}\text { Latent phase } \\
\text { (n=100) }\end{array}$ & 73 & 25 & 2 \\
\hline $\begin{array}{l}\text { Early active } \\
(\mathbf{n = 9 6 )}\end{array}$ & 73 & 24 & 1 \\
\hline $\begin{array}{l}\text { Late active } \\
(\mathbf{n = 9 5 )}\end{array}$ & 25 & 62 & 8 \\
\hline $\begin{array}{l}\text { Second stage } \\
(\mathbf{n = 8 7})\end{array}$ & 25 & 59 & 3 \\
\hline
\end{tabular}

Eric et al in their study monitored 898 women in labour with singleton pregnancy of more than 32 weeks period of gestation by continuous CTG. ${ }^{15}$ One hour prior to delivery the authors classified the FHR tracings as per three tier system into normal, fetal stress and fetal distress similar to that of present study but with a different nomenclature. Thus, normal tracing in their study was synonymous to category I FHR tracings, fetal stress was same as category II tracings and fetal distress was equal to category III tracings.

When Apgar score was analysed in relation to categories of FHR tracings, patients with category I tracings none of the neonates had Apgar score $<7$ at 1 minute. There was a significant increase in the incidence of apgar score $<7$ at 1 minute being $45 \%$ in category II $(9 / 20)$ and $55 \%$ in category III $(11 / 20)$. Eric et al in their study observed a similar trend in Apgar score less than 7 at 1 minute with the lowest incidence in neonates with normal tracings being $5 \%$, followed by $18 \%$ in the stress group and highest incidence i.e. $75 \%$ in the fetal distress group $(\mathrm{p}<0.001$ for trend $) .{ }^{15}$

In the present study, mean umbilical cord blood $\mathrm{pH}$ across the 3 FHR tracing categories i.e. category I, II and category III was $7.31 \pm 0.04,7.26 \pm 0.05$ and $7.19 \pm 0.04$ 
respectively. Study by Eric et al also showed a similar progressive worsening of cord blood $\mathrm{pH}(7.27 \pm 0.06$, $7.21 \pm 0.08$, and $7.06 \pm 014 ; \mathrm{p}<0.05)$ for normal, fetal stress and fetal distress groups respectively. ${ }^{15}$

In the present study, it was observed that all patients $(8 / 8)$ with category III FHR tracings and $18 / 62$ patients $(29 \%)$ with category II FHR tracings required NICU admission $(p=0.001)$. This was in agreement with the findings of Eric et al who also found a significant rise in admission to NICU with increase in the severity of FHR tracings being $5.6 \%, 10.6 \%$, and $37.5 \%(\mathrm{p}<0.05)$ for normal, fetal stress and fetal distress respectively. ${ }^{15}$

\section{CONCLUSION}

Intrapartum electronic fetal monitoring is useful in patients with FGR pregnancies during labour. 3-tier system of categorizing FHR tracings into category I, II and III is helpful to distinguish the neonates who have a high likelihood of normal outcome from those neonates who are at high risk for fetal hypoxia. Category I FHR tracings during active phase of labour accurately predicts the neonates who are likely to have normal neonatal outcome. Category III tracings are highly predictive of neonates who have high probability of adverse neonatal outcome. Thus, intrapartum FHR monitoring is strongly recommended in pregnancy with FGR.

Category II tracings which is an intermediate category however is unable to distinguish accurately the neonates who are likely to have normal outcome from those who may have adverse outcome irrespective of results of fetal surveillance tests. Therefore, there is a need to look into the individual parameters which define this category. Clearly defined categories like category I and category III tracings can be used to predict the outcome in day to day practice. When the category II tracings are present, it requires more vigilant monitoring and decision taking.

\section{Funding: No funding sources}

Conflict of interest: None declared

Ethical approval: The study was approved by the Institutional Ethics Committee

\section{REFERENCES}

1. Beard RW, Filshie GM, Knight CA, Robert GM. Intensive care of high risk fetus in labour. J Obstet Gynecol Br Commonw. 1971;78:865-70.

2. Gabert HA, Stenchever MA. Continuous electronic monitoring of fetal heart rate during labour. Am J Obstet Gynecol. 1973;115:919-24.

3. Paul RH, Hon EH. Clinical fetal monitoring. Am J Obstet Gynecol. 1974;118:529-33.

4. Liston R, Sawchuk D, Young D. Society of Obstetrics and Gynecologists of Canada, British
Columbia Perinatal Health Program. Fetal health surveillance: antepartum and intrapartum consensus guideline. J Obstet Gynaecol Can. 2007;29(Suppl):356.

5. Winkler CI, Hauth JC, Tucker JM, Owen J, Brumfield CG. Neonatal complications at term as related to the degree of umbilical artery academia. Am J Obstet Gynecol. 1991;164(2):637-41.

6. Royal College of Obstetricians and Gynecologists. The use of electronic fetal monitoring: The use and interpretation of cardiotocography in intrapartum fetal surveillance. Evidence-based clinical guideline No.8 London, UK: RCOG Press; 2001.

7. Macones GA, Hankins GD, Spong CY, Hauth J, Moore T. The 2008 National Institute of Child Health and Human Development workshop report on electronic fetal monitoring. Update on definition, interpretation, and research guideline. Obstet Gynecol. 2008;112:661-6.

8. Okai $\mathrm{T}$, Ikeda $\mathrm{T}$, Kawarabayash $\mathrm{T}$, Kozuma $\mathrm{S}$, Sugawara J, Chisaka $\mathrm{H}$, et al. Intrapartum management guidelines based on fetal heart rate pattern classification. J Obstet Gynaecol Res. 2010;36(5):925-8.

9. Mandruzzato G, Antsaklis A, Botet F, Chervenak FA, Figueras F, Grunebaum A, et al. Intrauterine restriction (IUGR). J Perinat Med. 2008;36(4):27781.

10. Bukowski R. Stillbirth and fetal growth restriction. Clin Obstet Gynecol. 2010;53(3):673-80.

11. De Onis M, Blossner M, Villar J. Levels and patterns of intrauterine growth retardation in developing countries. Eur J Clin Nutr. 1998;52(1):5-15.

12. American College of Obstetricians and Gynecologists 2009. ACOG practice bulletin no. 106: Intrapartum fetal heart rate monitoring: nomenclature, interpretation, and general management principles. Obstet Gynecol. 114(1):192202.

13. International Federation of Gynecology and Obstetrics Workshop on the Guidelines for the use of fetal heart rate monitoring. Int $\mathbf{J}$ Gynaecol Obstet. 1987;25:159-67.

14. Blackwell SC, Grobman WA, Antoniewicz L, Hutchinson M, Bannerman CG. Interobserver and intraobserver reliability of the NICHD 3-tier FHR Interpretation System. Am J Obstet Gynecol. 2011;205:378.e1-5.

15. Dellinger EH, Boehm FH, Crane MM. Electronic FHR monitoring: Early neonatal outcomes associated with normal rate, fetal stress and fetal distress. Am J Obstet Gynecol. 2000;182:214-20.

Cite this article as: Bhavya HU. Evaluation of categories of intrapartum fetal heart rate tracings in pregnancies complicated with fetal growth restriction and its relation to perinatal outcome. Int J Reprod Contracept Obstet Gynecol 2021;10:1128-33. 